\title{
Is Euler's circle a symbol or an icon?
}

\author{
Amirouche Moktefi \\ Chair of Philosophy, Tallinn University of Technology \\ Akadeemia tee 3, 12618 Tallinn, Estonia \\ e-mail: amirouche.moktefi@ttu.ee
}

\begin{abstract}
The most familiar scheme of diagrams used in logic is known as Euler's circles. It is named after the mathematician Leonhard Euler who popularized it in his Letters to a German Princess (1768). The idea is to use spaces to represent classes of individuals. Charles S. Peirce, who made significant contributions to the theory of diagrams, praised Euler's circles for their 'beauty' which springs from their true iconicity. More than a century later, it is not rare to meet with such diagrams in semiotic literature. They are often offered as instances of icons and are said to represent logic relations as they naturally are. This paper discusses the iconicity of Euler's circles in three phases: first, Euler's circles are shown to be icons because their relations imitate the relations of the classes. Then, Euler's circles themselves, independently of their relations to one another, are shown to be icons of classes. Finally, Euler's circles are shown to be iconic in the highest degree because they have the relations that they are said to represent. The paper concludes with a note on the so-called naturalness of Euler's circles.
\end{abstract}

Keywords: iconicity, Charles Peirce, homomorphism, Euler diagram, Venn diagram, logic diagram, linear diagram, Leibniz, line of identity, notation, naturalness, formalization

Euler adopts a circle to represent a set. Is Euler's circle a symbol or an icon? This is a classic question that shows that the distinction between a symbol and an icon is sometimes not clear-cut. (Shin 2002: 26)

\section{Introduction: Iconicity}

It is not rare to meet with Euler's circles in recent literature on iconicity (Ambrosio 2010; Giardino, Greenberg 2015). One reason might be the central role of diagrams in the understanding of iconicity (Stjernfelt 2000). Also, their seemingly indisputable 
iconicity makes Euler's circles ideal pedagogical devices to explain and illustrate what iconicity stands for. Charles S. Peirce made high claims for this Eulerian scheme of diagrams and argued that its "beauty - a violent inappropriate word, yet apparently the best there is to express the satisfactoriness of it upon mere contemplation - and its other merits, which are fairly considerable, spring from its being veridically iconic, naturally analogous to the thing represented, and not a creation of conventions. It represents logic because it is governed by the same law" (CP 4.368). Euler's circles are said to represent logic relations "as they really are" but it is not clear why they do so. We are rather often asked to grant their claimed naturalness and intuitiveness. These properties would, however, remain mysterious if we do not inspect the working of these diagrams and what they actually represent. The aim of this paper is to discuss the iconicity of Euler diagrams. We will not dispute their iconicity since there is plenty of evidence of it on minimal grounds. That would suffice to explain why they do work. We will rather attempt to demonstrate their higher iconicity, and as such explain why they are allegedly said to work so well.

As is well-known, the very idea of iconicity is problematic. It has long been disputed and still is among Peirceans, semioticians and beyond (Stjernfelt 2011; Morgagni, Chevalier 2012). It is not the object of this paper to address these disputes. We will rather rely on a basic toolkit of three claims on Peirce's theory of iconicity that we believe are little subject to criticism and would meet general acceptance: (1) an icon resembles its object; (2) resemblance needs not to be physical; (3) some icons are more iconic than others. Although each claim might give rise to interpretations and disapprovals as to its relevance, applicability and scope, the belonging of each to Peirce's theory of iconicity is less disputable and would be granted by most Peirce's scholars. These claims are broadly reported in Peircean literature and can easily be evidenced in Peirce's writings. Although it has compellingly been argued that Peirce lacked a consistent theory of resemblance (Chevalier 2015), we still observe that Peirce did regularly define iconicity in terms of resemblance or likeness: "[An icon is a] sign which stands for something because it resembles it" (CP 3.362). We are also told that such resemblance is not necessarily physical: "Many diagrams resemble their objects not at all in looks; it is only in respect to the relations of their parts that their likeness consists" (CP 2.282). Hence, diagrams and algebraic formulae have equal claims to be recognized as icons, as long as they fulfill this criterion of homomorphism. This likeness of relations makes it possible to discover through the icon other truths concerning its object. However, equal claims to iconicity do not make all icons equally iconic. That iconicity is seen in degrees in Peirce's theory is manifest in his affirmation that "A diagram ought to be as iconic as possible, that is, it should represent relations by visible relations analogous to them" (CP 4.432). 
This toolkit suffices for our inquiry. Incidentally, we would like to add two specific observations. First, the fact that homomorphism is justifiably used as a basic criterion of iconicity does not infringe the first claim that makes resemblance the source of iconicity. Indeed, homomorphism is for Peirce, precisely, a criterion for resemblance, understood broadly. It is, thus, disputable to argue against resemblance (Ambrosio 2010: 152). All one has to keep in mind is that resemblance need not to be physical to be an icon, although physical resemblance might help to be more iconic. Second, varieties of iconicity have been defined in semiotic literature. Of particular interest for us, Frederik Stjernfelt (2011) distinguishes between operational iconicity and optimal iconicity, which sketchily refer to the ideas of being iconic and being more iconic respectively. We do not believe these conceptions necessarily engage distinct types of iconicity, but we will regularly refer to them as they address central issues in our paper.

\section{Some iconicity}

Before inspecting the iconicity of Euler's circles in the following sections, it might be useful to briefly remind what an Euler's circle is. These circles are named after mathematician Leonhard Euler who made a thorough use of them in the second volume of his Letters to a German Princess (1768). The idea looks quite simple: a term is represented by a circle. For instance, the term Greek might be represented by circle $A$ (Figure 1a). Then, Propositions could be expressed by the relations of the circles: for instance, if circle $B$ stands for Human, then the proposition "All Greeks are Humans" is represented by a diagram where circle $A$ is inside circle $B$ (Figure 1b). Finally, arguments involving several propositions can be represented to discover new information: If it is known that "All Greeks are Humans" and that "All Humans are Mortals", the representation of these propositions in a diagram, where circle $C$ stands for Mortal, shows that "All Greeks are Mortals" as well (Figure 1c).


Figure 1a.

Figure $1 b$.

Figure 1c. 
Euler made high claims for this system of diagrams which he believed to be "extremely commodious for facilitating our reflections on this subject, and for unfolding all the boasted mysteries of logic, which that art finds it so difficult to explain; whereas by means of these signs the whole is rendered sensible to the eye" (Euler 1833: 340-341). Euler was not alone in his enthusiasm. A century later, when Peirce came to the scene, Euler's circles were commonly used in logic textbooks.

There seems to be an undisputable agreement as to the iconicity of Euler diagrams. This iconicity is demonstrated by the homomorphism between the topological relations that rule the circles and the logical relations of the terms: "The visually observable relation - $f$ being inside the circle - resembles the membership relation between an object and a set: If object $f$ is a member of set $A$, then we say $f$ is in set A. Because this homomorphic relation is a quite intuitive one, we do not need any extra convention for it, unlike with the symbol ' $E$ '. Even though it is not clear whether a circle itself is a symbolic or an iconic representation of a set, it is clear that the relation 'being a member of' is iconically (not symbolically) represented when we write ' $f$ inside a circle" (Shin 2002: 26). This likeness of relations suffices to establish the iconicity of Euler diagrams as a whole. There is no need to address the iconicity of the circles themselves, considered independently. The minimal criterion of iconicity is fulfilled thanks to this "structural correspondence between topology and semantics" (Burton et al. 2014: 54).

Peirce argued in many instances that "a great distinguishing property of the icon is that by the direct observation of it other truths concerning its object can be discovered than those which suffice to determine its construction" (CP: 2. 279). Let us, for the sake of illustration, consider the syllogism Celarent, previously worked out in Shin (2002: 32) and Ambrosio (2010: 159-160). Two premises are offered: "All $A$ are $B$ " and "No $B$ is $C$ ". Let circles $A, B$ and $C$ stand for terms $A, B$ and $C$ respectively. The first premise is represented by drawing circle $A$ inside circle $B$ (Figure 2a). The second premise asserts that $B$ and $C$ are disjoint. This information is added to the previous figure by drawing circle $C$ outside circle $B$, regardless of the relation between circles $A$ and $C$ (Figure 2b). It will directly be observed on the resulting diagram that "No $A$ is $C$ ".



Figure $2 a$.
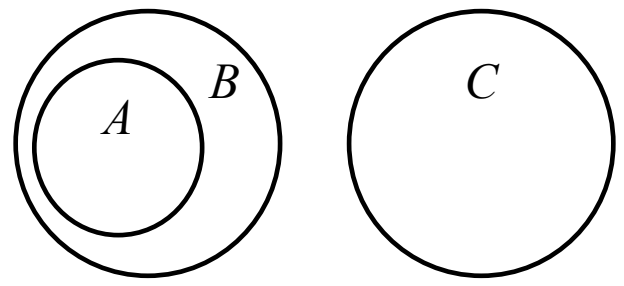

Figure $2 b$. 
The working of these diagrams seems so simple that one might wonder why it works so well. It is often argued, as Peirce did in the above quotation, that the force of these diagrams comes from their naturalness. They are said to represent relations as they "really" are. But this would just push the question further: where does that naturalness spring from and why would logic and space be governed by the same laws? After all, our logical conceptions are not necessarily spatial. Umberto Eco argues that " $[t]$ he fact of being or not being passionate is not a matter of space. It is at most, to speak in traditional logic words, a matter of possessing or not possessing a given propriety. Why does traditional logic translate this possession and non-possession in terms of belonging and non-belonging to a class? By pure convention" (Eco 1980: 228).

Eco rightly reminds us that concepts might very well be understood as the possession of proprieties (or attributes) rather than the belonging to a class. Actually both interpretations have long been used in logic and were known under different denominations. For convenience, we will refer to them as 'intension' and 'extension', although Peirce himself usually adopted the Hamiltonian terms 'depth' and 'breadth' (Moore et al. 1984: 74). Broadly understood, 'intension' refers to the attributes that are involved in a term while extension refers to the individuals to whom the term refers (Venn 1894: 453-476; Keynes 1906: 22-47; Shearman 1906: 133-142). Although Eco suggests in the above quotation that the extent of a term would be a conventional derivation of its intent, both interpretations seem rather equally legitimate to express a term: "In speaking thus of intension and extension as if they could be regarded apart, we must of course remember, not merely that the existence of each (generally speaking) postulates the existence of the other, but that this existence is actually more or less in evidence, and can only be neglected by an act of conscious abstraction. That is, we cannot help knowing, in the one case, that a class, actual or potential, corresponds to each group of attributes, just as in the other we know that each class was, or might be, determined by its distinctive attributes. But in each case alike we can, for the purpose of discussion, consider one aspect alone" (Venn 1894: 455).

As far, we described Euler diagrams that do represent terms in their extent. Since there are no a priori reasons to favour one interpretation over the other, it would be interesting to observe what a scheme of spatial diagrams would look like if one appeals to intent. Let there be a term $B$ whose intent is the attribute $b$. Now, let us have a term $A$, whose attributes are $b$ and $a$. In extension, term $A$ gathers the individuals who have both properties $a$ and $b$. Hence, $A$ is included in and has a smaller extent than $B$. In intension however, $A$ is "wider" since its group of attributes $\{a, b\}$ includes that of $B\{b\}$. "The more the intension, the less the extension, and conversely" (Venn 1894: 470). The intensional interpretation might look awkward to the modern reader, but history shows that such schemes did exist and that they were even favoured by some logic traditions (Dipert 1991: 142-147). For instance, Leibniz worked with 
both interpretations although he demonstrated a "mechanical and almost instinctive" preference for intension (Couturat 1901: 23).

In a diagrammatic scheme founded on intension, a term $A$ (respectively $B$ ) is represented with a circle that gathers all the attributes that are predicated of $A$ (respectively $B$ ). Hence, a proposition asserting that "Every $A$ is $B$ " would be represented by a circle $B$ inside a circle $A$ (Fig. $3-$ a). Indeed, any subject predicated with all the attributes of $A$ necessarily is also predicated with all the attributes of $B$. It might be said that the relation of the circles reflects the relation of the terms, and as such, this intensional representation has equal claim for minimal iconicity as the extensional representations previously described.

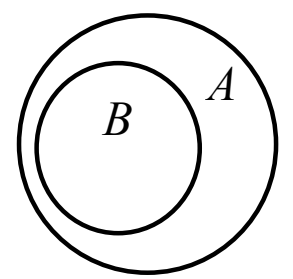

Figure $3 a$.
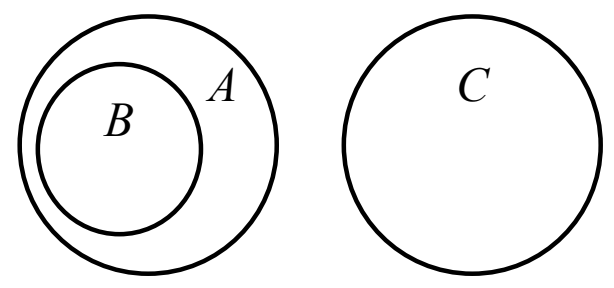

Figure $3 b$.

For the sake of comparison, let us now consider an intensional interpretation of the example discussed above: Celarent. We are told that "Every $A$ is $B$ " and that "No $B$ is $C$ ". The first premise is represented in Figure 3a. Now, the second premise asserts that $B$ and $C$ have disjoint groups of attributes. It follows that circle $C$ must be outside circle $B$. But it is not clear what the relation between circles $A$ and $C$ should be. Let us consider a subject $X$ which is $A$ (i.e. is predicated with all the attributes of $A$ ). This subject $X$ is also $B$ (because it also necessarily has all the attributes of $B$ ). Since no subject can be both $B$ and $C$, it follows that $X$ cannot be $C$. Hence, $A$ and $C$ must be disjoint (Figure $3 \mathrm{~b}$ ). We should observe, however, that this logical impossibility is physically possible: one might for instance draw circle $C$ inside circle $A$ without violating the premises. Hence, a diagrammatic solution would not explain why the disjointness of $B$ and $C$ would necessarily keep $C$ outside $A$. Louis Couturat invokes a "kind of repulsion, rather moral than physical" between terms $B$ and $C$, that resists geometrical representation (Couturat 1901: 22).

The failure of intensional diagrams to work as efficiently as extensional ones might come as a surprise given that they similarly fulfil the minimal requirements of iconicity. There are no a priori reasons to prefer the interpretation of a term $A$ as extensively included in $B$ rather than intensively containing it. Both interpretations 
lead to diagrams where relations of terms are represented by relations of circles. So what went wrong? We would suspect that there is something about extension that makes it lend itself better than intension to spatial formalization. In order to explore this path, we need to consider how the extension of a term is represented. As far we addressed the iconicity of Euler's circles, merely in their relations to one another, regardless of the semiotic properties of a single Euler's circle considered independently. In the following, we will rather inspect how an Euler's circle stands for a term, regardless of its relations to other circles.

\section{More iconicity}

Before proceeding to how a circle actually represents a class, it is crucial to consider two concepts that are more complex than they might appear at first: classes and circles. A class, understood as the extension of a term, is a collection of the individuals to whom the term refers. The formation of classes is performed with either of two mental processes known to 19th-century logicians as classification and division (Carroll 1897: 1-4; Keynes 1906: 441-449). In classification, individuals are put together in a group as to form a class (Figure $4 \mathrm{a}$ ) while division forms sub-classes out of an existing class (Figure 4b). In our illustrations, both processes yield to the formation of the same class that has three individuals. It will be observed that the state of the outer individuals differs: division simultaneously makes them form a complementary class while classification does not. Negative terms have long been a matter of dispute in traditional logic and their treatment significantly impacted the history of logic diagrams (Moktefi, Shin 2012: 632-637). However, this issue should not concern us in this paper, since Euler's diagrams as we discuss them represent classes that are formed by classification and, thus, do not pay attention to the outer class.

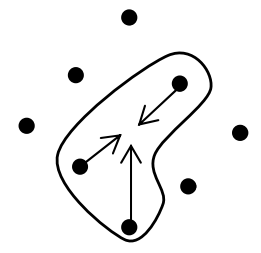

Figure 4a.

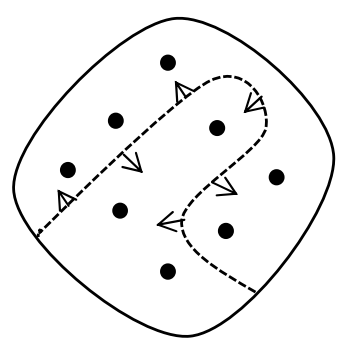

Figure $4 b$.

Classes, as defined above, should not be confused with sets as commonly understood in modern theories of collections. A class is formed by individuals while a set contains 
them. Inversely, individuals are part of the class they form but belong to their set. We shall illustrate this crucial difference by observing a whole cake in a box (Figure 5a). Let the cake be divided into four parts (Figure 5b). Those parts form the cake but are said to be contained in the box. It would be awkward to say about those parts that they are contained in the cake. Similarly, individuals are not inside a class, they are the class. Now suppose one part alone is left (Figure 5c). Presently, that part is the cake. Similarly, one does not distinguish an individual from a singleton-class: the (lonely) individual is the class. Hence, class theory is a 'part-whole theory' of collections that does not differentiate relations of membership and inclusion, while set theory does. Now imagine all parts disappeared (Figure 5d). We would say that the cake does not exist anymore while the box will be said to be empty. Classes and sets stand similarly: a class does not exist when there are no individuals to form it while a set does and is simply said to be empty. These differences are crucial to understand the development of modern logic. Peirce made significant contributions to both theories of collections, but his logic still worked mainly with class theory (Dipert 1997; Grattan-Guinness 1997: 29-30).



Figure $5 a$.

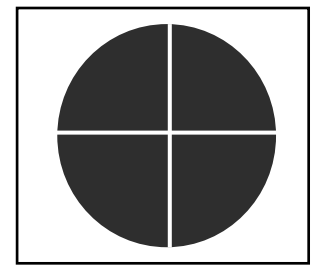

Figure $5 b$.

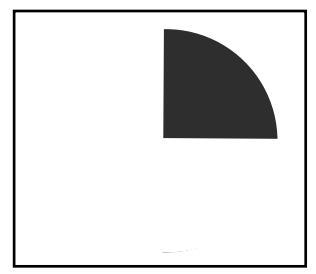

Figure 5c.

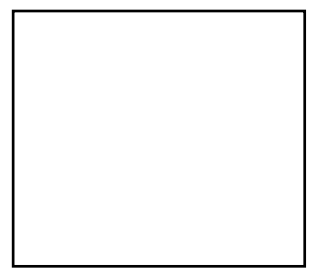

Figure 5d.

As intuitive as it might look, the idea of a circle also deserves some explanation. Indeed, we hastily tend to think of a circle as a "circular line" (Figure 6a) while it should be thought of as a space. In Euclid's Elements, a circle is defined as "a plane figure contained by one line such that all the straight lines falling upon it from one point among those lying within the figure are equal to one another" (Heath 1908: 153). The line that "contains" the circle is not formally defined but is labelled its 'circumference' (Heath 1908: 154). The common confusion between the circle and its circumference is well documented in the history of mathematics (Goldstein 1989). For our purpose, it is important to keep in mind that a circle is a plane figure. As such it is formed by the points within its circumference. That circumference itself does not exist as a separate object. It simply contains all the points that are the furthest from the centre of the circle, but are still part of that circle. It is for pure convenience that we commonly represent it as a circular line. Hence, we should not fail to keep in mind that the circle is what is within the curve, including the curve (Figure 6b). The dots within the 'circular line' are not inside the circle, they are the circle. 


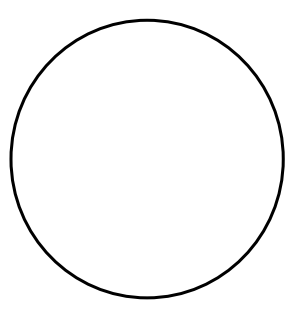

Figure $6 a$.

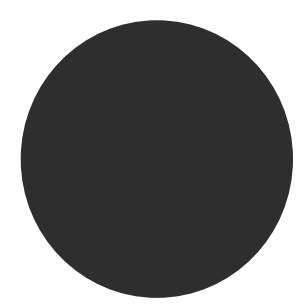

Figure $6 b$.

Now that we have in mind what classes and circles really are, we can better undertake the crucial task of understanding how a circle stands for a class. Surprisingly, this question is seldom addressed in literature on the ground that it is the arrangement of the circles, not the circles themselves, which makes Euler diagrams iconic. As far as it has been possible to check, Peirce himself did not openly address the question. Yet, some scholars hold him to be of the opinion that the correspondence between classes and circles is purely conventional (Dipert 1996: 389). Eco has the merit of clarity: "But is belonging to a class a spatial fact? Sure it is not, except the fact that I might be defined to belong to the class of all those who are located in a certain place; but if I belong to the class of those who are passionate, this class would be an abstraction, not a space. Why, in the representation with circles, does the class become a space? By pure convention" (Eco 1988: 228-229). There is a delightful irony in this argument: although meant to evidence that belonging to a class is not a spatial fact, Eco himself opens the way for one exception, "the fact that I might be defined to be belong to the class of all those who are located in a certain place". That is precisely how Euler's circles proceed.

Let us go back to Euler and how he introduced his circles. They first appear in Letter 102, dated 14 February 1761, where he explains how to represent the four traditional types of propositions with the help of his circles: "These four species of propositions may likewise be represented by figures, so as to exhibit their nature to the eye. This must be a great assistance towards comprehending more distinctly wherein the accuracy of a chain of reasoning consists. As a general notion contains an infinite number of individual objects, we may consider it as a space in which they are all contained. Thus, for the notion of man we form a space [...] in which we conceive all men to be comprehended" (Euler 1833: 339). We should not pass these constructions too hastily. The idea is not to merely establish a correspondence between the collection of individuals and a space, but rather to gather the individuals within that space. For the class of men, one has to gather all men in a single space. That space is its Euler circle. It does not matter whether that gathering is actually feasible since we are proceeding by the mental process of classification. The class itself collects "possibilities of a certain description" and is, as such, an abstraction (CP 4.351, 4.370). 
It might be rightly objected that Euler explicitly holds his circles to represent the "general notion" of man rather than, properly, the class of men. This is unquestionably true. Euler's syllogistic theory itself is mainly described intensionally. However, Euler also explicitly worked out his diagrams extensionally. As suspicious as this might look, Euler was not unique in this respect. The logician William S. Jevons, for instance, proceeded similarly (Venn 1894: 453; Shearman 1906: 7). This simply shows that those logicians, despite their intentional approach to logic, understood that extension still lends itself better to logical calculus, be it diagrammatic or symbolic. The extension of a term is formed by a physical gathering of its individuals like a flock of sheep. This flock covers a space. That space is the Euler's circle of that class. Hence, that Euler's circle truly is the space on which the extension stands. The division of that space unsurprisingly yields a division of the space on which the class physically stands, not because they imitate each other's spatial properties but because they are the one and very same space.

It might also reasonably be objected to our reading that a group of two lambs, for instance, does not look at all like a circle. But it must be kept in mind that it is not properly a class of lambs that is meant to be represented by Euler's circles, but a class of (whatever) individuals. Every dot of the circle (not inside the circle) represents an individual of the class. Hence, although a lamb might not look at all like a bike, yet a class of lambs looks exactly like a class of bikes. The labelling of the classes is indeed performed by conventional marks (as will be discussed later), but that does not affect the iconic representation of the class itself, the same way names of cities and countries are inserted on maps that are iconic themselves. Furthermore, the shape of the figures does not matter and need not to be circles at all. Euler warned us that "it is of no importance of what figure they are", as long as they are spaces (Euler 1833: 340 ). Hence, the appeal to circles is for pure convenience, although it impacts on the understandability of the diagram (Blake et al. 2014). Actually, it is even possible to imagine a class bounded in several spaces but that would be an unnecessary, useless and tedious practice. Continuous figures are thus preferred (Moktefi et al. 2014). There are no considerations of size either, since it is the topological (not the metrical) properties of the diagrams that are of interest to us. In a sense, an Euler circle might be conceived as a map of the gathering of individuals in a territory they shape. The circumference is the border of the territory. Sub-classes would be depicted as regions of that territory. Such maps do not need to have metric properties; topology and structure suffice (Stjernfelt 2000: 374-375). 


\section{Highest iconicity}

Euler's circles were held to resemble a class on the ground of the structure relations they share. This homomorphism suffices to establish the iconicity of Euler's circles and to explain their ability to carry syllogistic reasoning. Symbolic notations share those structure relations as well, and thus have equal claim to iconicity. Yet Euler diagrams were held to exhibit those relations better: "A comparison of Euler's diagram and the notation " $S \in M$ " shows that the diagram represents the relation of membership between an object and a set in a more natural and immediately observable way. Strictly speaking, however, no physical resemblance is noticed between the diagram and the state of affairs that it stands for" (Ambrosio 2010: 155). It was not clear where that naturalness spring from if the diagrams had no physical resemblance to their objects. In the previous section, however, we argued that the very idea of an Euler's circle is achieved on the grounds of a physical resemblance. That does not affect their shared structure relations but provides a source that might explain the naturalness of Euler's circles and their claimed superiority over symbolic notations to exhibit logic relations.

Let us consider inclusion. To express the inclusion of a class $A$ in another class $B$, roughly corresponding to the proposition: "All $A$ are $B$ ", several symbolic techniques might do. Early symbolic logicians considered the equation to be the cornerstone of logic, and as such attempted to express this relation of inclusion with the expression: ' $A=A . B$ '. This notation actually states the identity of two classes: $A$ and $A . B$, the latter being the portion common to $A$ and $B$. Another solution, adopted by Peirce and commonly used since, consists in introducing a new symbol (' $\subset$ ' for instance) to mark inclusion. Hence, we would write: ' $A \subset B$ '. This notation avoids the replication of $A$, but still requires the introduction of a conventional sign, as suggestive as it might be, to express the relation. This does not prevent these symbolic expressions to be icons of the logic relation they express since they do fulfill the homomorphism criterion. Let us now turn to Euler diagrams and inspect how they represent the relation of inclusion. Our purpose is to demonstrate that they hold a much higher degree of iconicity and that they do not appeal to convention in order to represent inclusion.

To reach our purpose, we need to introduce the concept of a 'Line of identity' that Peirce used in his Existential graphs and held to be iconic in the highest degree (Pietarinen 2006: 115-118; Stjernfelt 2011: 400-406). Without engaging in an exposition of Peirce's existential graphs, let us sketch what a 'Line of identity' is. First, let there be two dots on a sheet of paper to denote two individuals: 'Lewis Carroll' and 'Charles L. Dodgson'. The Line of identity connects the two dots to indicate that the individuals are identical (Figure 7a). Peirce claimed that the "line of identity is, moreover, in the highest degree iconic. For it appears as nothing but a continuum of dots, and the fact of the identity of a thing, seen under two aspects, consists merely 
in the continuity of being in passing from one apparition to another." (CP 4.448). The identity line prevents from using a conventional sign to indicate identity. It rather suggests that the two dots at its extremities are the very same object that moves along the line. As efficient as this innovation is, one might still be surprised to see Peirce praise it for being iconic "in the highest degree". Indeed, one might imagine that a higher iconicity would simply be reached if the very same dot denotes both individuals (Figure 7b). While the former scheme (Figure 7a) affirms that "Lewis Carroll is identical to Charles L. Dodgson", the latter scheme (Figure 7b) rather asserts that "Lewis Carroll is Charles L. Dodgson". Hence, the identity is not represented anymore; the identity is. Euler diagrams possess precisely this even higher degree of iconicity, as we will show.

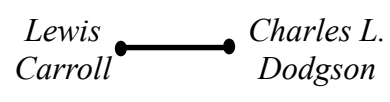

Figure $7 a$.

\section{Lewis \\ Carroll • Charles L. \\ Dodgson}

Figure $7 b$.

For the sake of transition, let us first illustrate our case with linear diagrams that were popular among traditional logicians (Englebretsen 1998; Bellucci et al. 2014; Moktefi, Shin 2012: 629-632). Leibniz designed such diagrams for syllogistic reasoning (Couturat 1903: 292-298). The principles are simple: terms are represented by parallel lines, and spatial relations between lines represent the logical relations between terms. In order to represent proposition "All $A$ are $B$ ", one simply draws parallel segment lines $A$ and $B$, representing terms $A$ and $B$, respectively, in such a way as to have segment line $A$ strictly under segment line $B$ (Figure $8 \mathrm{a}$ ).



Figure $8 a$.

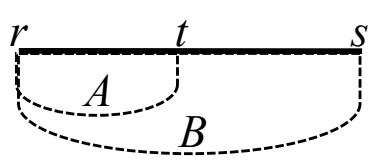

Figure $8 b$.

One might naively think that these diagrams differ from Euler diagrams in that it is the position of the segments to each other, not their topological relations, that indicates the logical relations. However, a close look shows that these linear diagrams actually proceed exactly as Euler's do: first, individuals are represented by dots and classes gather those individuals on lines (rather than spaces); then, relations of classes are 
expressed by the topological relations of the segments. For instance, proposition "All $A$ are $B$ " asserts that class $A$ is part of class $B$. Similarly, line segment $A$ is shown as part of line segment $B$. This is not evidenced by the position of the segments, but rather by the vertical dotted lines which set the limits of the segment under consideration. Those dotted lines extract a segment which is part of $B$, and that segment is said to be $A$. One could freely move line segment $A$ far away from line segment $B$ (in any direction), those dotted lines would still secure the identity of $A$ and the "extracted" part of $B$. Hence, those dotted lines act exactly as Peirce's lines of identity, although they are less iconic because of their discontinuity. At this stage, the idea of making this scheme of diagrams more iconic by making the segments coincide suggests itself, as we did for the dots in the line of identity. That is easy to achieve by keeping line segment $A$ within line segment $B$ (Figure $8 \mathrm{~b}$ ). In this new scheme, line segment $r t$ (which stands for class $A$ ) is part of line segment $r$ (which stand for class $B$ ). Contrary to the first scheme where each dot of segment $A$ was shown as identical to a dot from part of segment $B$, this second scheme shows that every dot of segment $A$ actually is a dot of segment $B$. As such, the second scheme is more iconic than the first. Now the interesting part of the story is that this second scheme was also known to Leibniz (Gerhardt 1890: 228-247). However, Leibniz preferred the first scheme, despite the loss of iconicity, presumably for its visual clarity (Couturat 1901: 25-26). The second scheme might prove difficult to manipulate, notably with further terms, unless one appeals to colours, for instance, to distinguish different segments. Still, logicians using parallel lines do accept the co-existence of segments on the same line when confusion is not possible. For instance, the representation of proposition "No $A$ is $B$ " can be simply achieved by drawing two disjoint segments $A$ and $B$ on the same line (Figure 9) (Lambert 1764: 113).

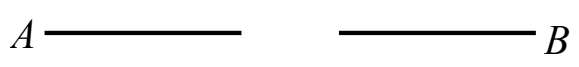

Figure 9.

Linear diagrams of the second scheme are truly linear in the sense of being onedimensional, with all segments on the same line. On the contrary, the first scheme is bi-dimensional since segments are on parallel lines. Consequently, it replicates the segments that stand for the joint portions of the classes. That replication is needless with Euler's circles which are already bi-dimensional. 


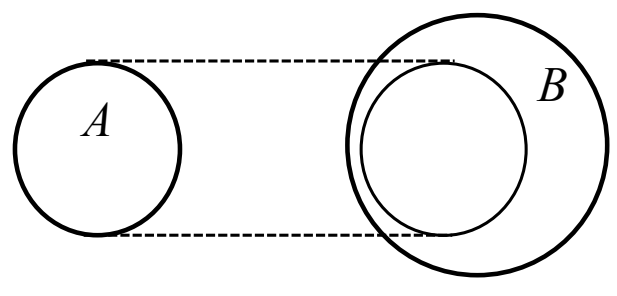

Figure 10a.

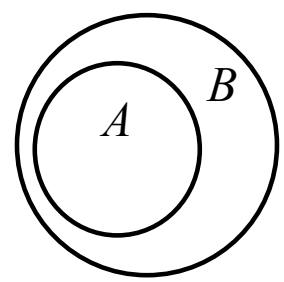

Figure 10b.

Let us consider proposition "All $A$ are $B$ ", which asserts that $A$ is part of $B$. If we were to replicate the circle that stands for the joint portion (i.e. $A$ ), in the same style as linear diagrams, we would get a diagram where $A$ would be represented by two circles whose identity would be expressed by the (dotted) lines of identity (Figure 10a). In a way, this diagram proceeds in the same way as the symbolic expression " $A=A$. $B$ ". Although it does fulfill its purpose, its loss of iconicity is not compensated by any gain of visual aid. Indeed, our classic Euler diagram for the same proposition clearly shows that circle $A$ is distinctly part of circle $B$ (Figure 10b). One might think that this diagram is conceived similarly to the notation ' $A \subset B$ '. However, that would be misleading. Indeed, in these Euler diagrams, every dot of circle $A$ is a dot of circle $B$. The inclusion of $A$ in $B$ is expressed by the fact that the individuals that form $A$ simultaneously form part of $B$. As such, classic Euler diagrams possess more than the 'highest degree' of iconicity. They dispense with the replication of the classes and with any conventional signs to represent the relation. There is no need to represent the inclusion of $A$ in $B$ because it is granted by the identity of $A$ and part of $B$. And there is no need to express the identity of $A$ and part of $B$ because $A$ is physically part of $B$. This result should not surprise us since we know that class theory does not distinguish membership and inclusion, as previously explained. Hence, we would expect the inclusion of a class in another to be represented in a manner similar to the 'membership' of an individual in a class. But we held in the previous section that 'membership' stands on physical resemblance. Hence, we argue here that inclusion stands on the same grounds. Once, Euler diagrams are conceived as maps of territories, one can easily see how some territories are part of larger ones. It suffices to single out Estonia and Europe on the world map to observe directly that the former is part of the latter, without the appeal to any convention to represent this relation. Similarly, in our Euler diagram, once classes $A$ and $B$ are formed, $A$ will be necessarily found to be part of $B$. Euler diagrams do not represent relations between classes; rather, they have those relations. 


\section{Conclusion: pure iconicity}

In this paper, we early adhered to the iconicity of Euler's circles on the ground of their structure relations. However, we claimed that this homomorphism does not suffice to explain their force over symbolic notations. Then, we argued for a physical resemblance between classes and circles in the construction of Euler's circles. We demonstrated that this iconicity dispenses with conventional signs to express relations, as is found in symbolic notations. The comparison of Euler's circles with what Peirce held to be the highest degree of iconicity demonstrated that Euler's circles were even higher. These successes might encourage us to wonder imprudently whether Euler diagrams would stand for pure icons. The answer is, naturally, negative. Peirce warns us that a "diagram is a representamen which is predominantly an icon of relations and is aided to be so by conventions. Indices are also more or less used" (CP 4.418). For if a circle is observed ink-on-paper, several readings are possible (Stjernfelt 2000: 366). The diagram still needs an aid to express what it stands for. In Euler's circles non-iconic elements are important: dots stand for individuals in a rather indexical mode and classes are labelled with marks that are conventionally written on the space (as Euler did) or its circumference (as was Peirce's use).

These conventions do not harm to the naturalness of the diagrams. It might be important at this stage to insist on the fact that this naturalness is not necessarily natural. This claim might look awkward at first but will easily be understood if we think of a picture that truthfully reproduces a landscape. Such a picture will be said to hold the naturalness of the landscape although it cannot be said to be natural. The picture is the result of technical devices used to shape the picture. Similarly, an Euler diagram is constructed in such a way as to represent logic relations naturally. It does not mean that logic and space are one and the same. We already quoted Peirce's claim that Euler's scheme "represents logic because it is governed by the same law". Furthermore, Peirce argues that "as far as logical dependence goes, the validity of the syllogism and the property of the Eulerian diagram depend upon a common principle. They are analogous phenomena neither of which is, properly speaking, the cause or principle of the other" (CP 4.355). Hence, to construct a notation that would carry syllogistic reasoning in its own, one has to construct it in such a way as to share that "same law" or "common principle" that Peirce alluded to.

Euler actually argued that the foundation of all valid syllogistic forms "is reduced to two principles, respecting the nature of containing and contained: I. Whatever is in the thing contained, must likewise be in the thing containing. II. Whatever is out of the containing, must likewise be out of the contained" (Euler 1833: 350). These laws seem to also govern the topological relations between (his) circles. And so do many symbolic notations. This structure relation (i.e. minimal iconicity) suffices to explain 
why Euler's diagrams work for syllogistic. But what makes them work so well is their highest iconicity thanks to the physical resemblance that has been created between the circles and the classes. It is difficult to attribute this view to Peirce, although his claim that Euler's circles were "veridically iconic" suggests a higher degree of iconicity than homomorphism. Eco objected to Peirce's claim: "Peirce writes that the beauty of these diagrams comes from their "true iconic" status (4.368), an expression that might suggest that the spatial configuration of the diagrams imitates a real spatial situation. If it was so, Peirce's iconism would be truly ingenious; because even if diagrams do show visually interiority and exteriority relations, that doesn't mean that those spatial properties are icons of other spatial properties!" (Eco 1988: 228). We attempted in this paper to contend that Euler diagrams are constructed in such a way as to truly imitate a spatial relation, thanks to a mental process that Peirce perfectly describes: "Imagine the entire collection of men and nothing else to be enclosed in the imaginary circle, $M "$ "CP 4.350).

Our claim would be misunderstood if it is taken to mean that logic and space are governed by the same laws. On second thoughts, Euler's circles do not work so well. History shows that they have regularly been adjusted, extended and improved by successive logicians, including Peirce himself. They are inappropriate for negative terms and impractical when the number of terms increases (Moktefi, Shin 2012). We previously argued that intensional interpretations in logic resist Euler's circles, but the argument could easily be converted: Euler's circles seem unsuitable for intensional interpretations. Hence, we should keep in mind that it is only a specific province of logic that is under consideration and it is within that particular region that those laws are considered. Furthermore, as is argued by philosophers of mathematics, formalizations, like other forms of mathematization, do reshape their objects (Roux 2011; Dutilh Novaes 2012). The use of Euler's circles opened the way to further extensional logics founded on the relations between classes rather than the predication of an attribute to a subject. Later on, when logician John Venn reformed Euler's circles, he made them stand for new logic objects, known as compartments, rather than classes (Moktefi 2013). The moral of the story is that when we reason with logic diagrams, we do not merely search for the best diagrams to reason with, we also look for the best logic to diagram with. ${ }^{1}$

1 This paper draws upon research supported by Estonian Research Council PUT 267 "Diagrammatic mind: Logical and communicative aspects of iconicity", Principal investigator Ahti-Veikko Pietarinen. Parts of this paper were previously presented at several international conferences, notably: L’Argumentation dans les images scientifiques, les images scientifiques dans l'argumentation (Università Iuav di Venezia, Venice, Italy, 16-17 April 2010), Extended problem solving symposium (Aarhus University, Denmark, 24-25 January 2013), Icon: the Helsinki metaphysical club workshop (University of Helsinki, Finland, 10 September 2014), Visual learning: Pictures, parables, paradoxes (Budapest University of Technology and Economics, 


\section{References}

Ambrosio, Chiara 2010. Iconicity as homomorphism: The case of Picasso's Guernica. In: Bergman, Mats; Paavola, Sami; Pietarinen, Ahti-Veikko; Rydenfelt, Henrik (eds.), Ideas in Action: Proceedings of the Applying Peirce Conference. Helsinki: Nordic Pragmatism Network, 151-162.

Bellucci, Francesco; Moktefi, Amirouche; Pietarinen, Ahti-Veikko 2014. Diagrammatic autarchy: Linear diagrams in the 17th and 18th centuries. In: Burton, Jim; Choudhury, Lopamudra (eds.), DLAC 2013: Diagrams, Logic and Cognition. (CEUR Workshop Proceedings 1132), 23-30.

Blake, Andrew; Stapleton, Gem; Rodgers, Peter; Cheek, Liz; Howse, John 2014. The impact of shape on the perception of Euler diagrams. In: Dwyer, Tim; Purchase, Helen; Delaney, Aidan (eds.), Diagrammatic Representation and Inference: Diagrams 2014 Proceedings. (LNAI 8578) Berlin-Heidelberg: Springer, 123-137.

Burton, Jim; Stapleton, Gem; Howse, John; Chapman, Peter 2014. Visualizing concepts with Euler diagrams. In: Dwyer, Tim; Purchase, Helen; Delaney, Aidan (eds.), Diagrammatic Representation and Inference: Diagrams 2014 Proceedings. (LNAI 8578) Berlin, Heidelberg: Springer, 54-56.

Carroll, Lewis 1897. Symbolic Logic. London: Macmillan.

Chevalier, Jean-Marie 2015. The problem of resemblance in Peirce's semiotics and philosophy. Versus: Quaderni di Studi Semiotici 120: 45-59.

Couturat, Louis 1901. La Logique de Leibniz. Paris : Félix Alcan.

- 1903. Opuscules et Fragments Inédits de Leibniz. Paris : Félix Alcan.

Dipert, Randal R. 1991. Individuals and extensional logic in Schröder's 'Vorlesungen über die Algebra der Logik'. Modern Logic 1(2/3): 140-159.

- 1996. Reflections on iconicity, representation, and resemblance: Peirce's theory of signs, Goodman on resemblance, and modern philosophies of language and mind. Synthese 106(3): 373-397.

- 1997. Peirce's philosophical conception of sets. In: Houser, Nathan; Roberts, Don D.; Van Evra, James (eds.), Studies in the Logic of Charles Sanders Peirce. Bloomington: Indiana University Press, 43-76.

Dutilh Novaes, Catarina 2012. Formal Languages in Logic: A Philosophical and Cognitive Analysis. Cambridge: Cambridge University Press.

Eco, Umberto 1988. Le Signe: Histoire et Analyse d'un Concept. Bruxelles: Editions Labor. Englebretsen, George 1998. Line Diagrams for Logic. New York: Edwin Mellen Press.

Hungary, 14-15 November 2014), 100 years of modern semiotics: Limits and perspectives on Peirce's theory of signs (Charles University, Prague, Czech Republic, 1-2 November 2014). The author would like to express his gratitude to the participants who attended these events and contributed to the shaping of this paper with their comments and suggestions. The author would like to give special thanks to Catherine Allamel-Raffin, Francesco Bellucci, JeanMarie Chevalier, Jelena Issajeva, Claudio Paolucci, Ahti-Veikko Pietarinen, Sun-Joo Shin and Frederik Stjernfelt. All quotations from sources in French have been translated by the author. 
Euler, Leonard 1833. Letters of Euler on Different Subjects in Natural Philosophy Addressed to a German Princess. Vol. 1. New York: J. \& J. Harper.

Gerhardt, Carl I. (ed.) 1890. Die Philosophischen Schriften von Gottfried Wilhelm Leibniz. Vol. 7. Berlin: Weidmann.

Giardino, Valeria; Greenberg, Gabriel 2015. Introduction: varieties of iconicity. Review of Philosophy and Psychology 6: 1-25.

Goldstein, Catherine 1989. L’un est l’autre: Pour une histoire du cercle. In : Serres, Michel (ed.), Eléments d'Histoire des Sciences. Paris: Bordas, 129-149.

Grattan-Guinness, Ivor 1997. Peirce between logic and mathematics. In: Houser, Nathan; Roberts, Don D.; Van Evra, James (eds.), Studies in the Logic of Charles Sanders Peirce. Bloomington: Indiana University Press, 23-42.

Heath, Thomas L. (ed.) 1908. The Thirteen Books of Euclid's Elements. Vol. 1. Cambridge: Cambridge University Press.

Keynes, John Neville 1906. Studies and Exercises in Formal Logic. London: Macmillan.

Lambert, Johann Heinrich 1764. Neues Organon. Vol. 1. Leipzig: Wendler.

Moktefi, Amirouche 2013. La représentation visuelle des classes dobjets. Visible 10: 153-164.

Moktefi, Amirouche; Bellucci, Francesco; Pietarinen, Ahti-Veikko 2014. Continuity, connectivity and regularity in spatial diagrams for $\mathrm{N}$ terms. In: Burton, Jim; Choudhury, Lopamudra (eds.), DLAC 2013: Diagrams, Logic and Cognition (CEUR Workshop Proceedings 1132), 31-35.

Moktefi, Amirouche; Shin, Sun-Joo 2012. A history of logic diagrams. In: Gabbay, Dov. M.; Pelletier, Francis J.; Woods, John (eds.), Logic: A History of its Central Concepts. (Handbook of the History of Logic 11.) Amsterdam: North-Holland, 611-682.

Moore, Edward C; Fisch, Max H.; Kloesel, Christian J. W.; Roberts, Don D.; Ziegler, Lynn A. (eds.) 1984. Writings of Charles S. Peirce: A Chronological Edition, Vol. 2. Bloomington: Indiana University Press.

Morgagni, Simone; Chevalier, Jean-Marie 2012. Iconicité et ressemblance: une remontée sémiotique aux sources de la cognition. Intellectica 58 (2): 91-171.

CP = Peirce, Charles S. 1931-1933. Collected Papers of Charles Sanders Peirce. Vols. 2-4. (Hartshorne, Charles; Weiss, Paul, eds.) Cambridge: Harvard University Press. [In-text references are to $C P$, followed by volume and paragraph numbers]

Pietarinen, Ahti-Veikko 2006. Signs of Logic: Peircean Themes on the Philosophy of Language, Games, and Communication. Dordrecht: Springer.

Roux, Sophie 2011. Pour une étude des formes de la mathématisation. In: Chabot, Hugues; Roux, Sophie (eds.), La Mathématisation comme Problème. Paris: Editions des Archives Contemporaines, 3-38.

Shearman, Arthur T. 1906. The Development of Symbolic Logic. London: Williams and Norgate. Shin, Sun-Joo 2002. The Iconic Logic of Peirce's Graphs. Cambridge: MIT Press.

Stjernfelt, Frederik 2000. Diagrams as a centerpiece of a Peircean epistemology. Transactions of the Charles S. Peirce Society 36(3): 357-384.

- 2011. On operational and optimal iconicity in Peirce's diagrammatology. Semiotica 186: 395-419.

Venn, John 1894. Symbolic Logic. London: Macmillan. 


\section{Круг Эйлера - символ или иконический знак}

Наиболее известные диаграммные схемы, используемые в логике, называются кругами Эйлера. Они изобретены математиком Леонардом Эйлером, который популяризировал их в своих Письмах к немецкой приниессе (1768). Круги используются для обозначения объема понятий и множеств элементов. Чарльз С. Пирс, который внес значительный вклад в теорию диаграмм, похвалил круги Эйлера за их «красоту», которая является следствием их истинной иконичности. И в наше время можно нередко встретить такие диаграммы в семиотической литературе. Часто их приводят в качестве примера иконических знаков, уточняя, что они представляют логические связи в их натуральном виде. Данная работа рассматривает иконичность кругов Эйлера в трех фазах. Сначала в работе утверждается, что круги Эйлера являются иконами, потому что их отношения подражают отношениям между классами. Затем в работе показано, что сами круги Эйлера, вне зависимости от их отношений друг с другом, являются иконами классов. Наконец, круги Эйлера в высшей степени иконичны, потому что у них есть те отношения, которые они представляют. Статья завершается примечанием о так называемой натуральности кругов Эйлера.

\section{Kas Euleri ring on sümbol või ikoon?}

Loogikas kasutatavat kõige tuntumat diagrammiskeemi tuntakse Euleri ringide nime all. Neile on antud nimi matemaatik Leonhard Euleri järgi, kes populariseeris neid oma Kirjades saksa printsessile (1768). Nende mõte on esindada indiviidide klasse ruumiliselt. Charles S. Peirce, kes panustas oluliselt diagrammide teooriasse, kiitis Euleri ringe nende "ilu" tõttu, mis tuleneb nende tõelisest ikoonilisusest. Ka rohkem kui sajand hiljem võime semiootika-alases kirjanduses kohata taolisi diagramme. Sageli esitletakse neid ikoonide esinemisjuhtudena ja öeldakse, et nad esindavad loogilisi seoseid nii, nagu need loomupäraselt on. Käesolevas artiklis käsitletakse Euleri ringide ikoonilisust kolmes järgus. Kõigepealt näidatakse, et Euleri ringid on ikoonid, sest nende suhted matkivad klassidevahelisi suhteid. Seejärel näidatakse, et Euleri ringid ise, sõltumatult oma suhetest üksteisega, on klasside ikoonid. Lõpetuseks näidatakse, et Euleri ringid on kõrgeimal määral ikoonilised, sest neil on need suhted, mida nad väidetavalt esindavad. Artikli lõpetab märkus Euleri ringide nn loomulikkuse kohta. 